\title{
Development of community based rehabilitation in Thailand: A case study in Samut Sakhon Province
}

\author{
Tavee Cheausuwantavee
}

\begin{abstract}
Aims: To set up and conduct a community based rehabilitation (CBR) in urban area based on significant variables and particular conditions of previous meta-analysis studies. Methods: This study is participatory action research (PAR). The one particular community in Samut Sakhon Province, Thailand was purposively selected. The 13 CBR research participants were purposively and voluntarily recruited including officials of local, regional government and community hospital, volunteers, persons with disabilities (PWDs) and their care givers, and researchers. Verbatim of focus groups, participatory observations and field notes were undertaken. Those data were interpreted through thematic coding and analytic induction. Results: Community based rehabilitation project was purposively set up with four significant independent variables including age, education level, occupation or position, and work experience as characteristics of CBR workers suggested by previous meta-analysis. Participatory action research was still contributive strategy for CBR development in terms of mechanism
\end{abstract}

Tavee Cheausuwantavee

Affiliation: Associate Professor, Rehabilitation Services Department, Ratchasuda College, Mahidol University, Nakornprathom, Thailand.

Corresponding Author: Tavee Cheausuwantavee, 111 Ratchasuda College, Mahidol University, 4th Phuttamonton Road, Salaya, Phuttamonton District, Nakornprathom Province, Thailand, 73170; Email: tavee126@hotmail.com, tavee.che@mahidol.ac.th

Received: 10 April 2017

Accepted: 08 September 2017

Published: 09 September 2017 of consciousness raising, understanding collaboration and addressing CBR matrix. However, uncompleted PAR and CBR cycles, no more sectors of stakeholders and particular services with health focus of CBR matrix were limitation and challenges. Conclusion: This study proves that PAR with significant characteristics of participants is important CBR development. It will be more successful should other challenges of CBR will be also addressed.

Keywords: Community based rehabilitation, Community, Disability, Participation

\section{How to cite this article}

Cheausuwantavee T. Development of community based rehabilitation in Thailand: A case study in Samut Sakhon Province. Edorium J Disabil Rehabil 2017;3:79-88.

Article ID: 100034Do5TC2017

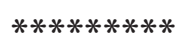

doi: 10.5348/Do5-2017-34-OA-10

\section{INTRODUCTION}

Community based rehabilitation (CBR) is still an active and alternative method to use for enhancing quality of life of persons with disabilities (PWDs) in community where no more rehabilitation services available in many countries and Thailand. The contributions of CBR include coverage and available services for PWDs, consciousness raising and enhancing positive attitudes of community towards PWDs, mental supports for PWDs and their families [1-4]. 


\section{EDORIUM Journals}

Edorium J Disabil Rehabil 2017;3:79-88.

www.edoriumjournals.com/ej/dr

However, there have been some challenges occurring in CBR conduction include

- negative attitude of majority community members towards PWDs and discrimination,

- lack of rigorous studies and effective CBR impact evaluation through more than the past two decades,

- $\quad$ lack of information and working skills of PWDs in business sectors/companies,

- no more cooperation among stakeholders and providers for PWDs as well as conducting by professional, governmental organizations or non-governmental organizations outside without more participation of community members and PWDs in community,

- $\quad$ poverty and non-service accessibility of PWDs [5-15],

- ineffective referral system,

- lack of budget for long run project,

- lack of appropriate knowledge and skills of service providers, teacher and CBR workers to serve PWDs [5,7,9,12,16-18].

On the other hand, even the more valid studies in CBR both qualitative and quantitative approach, but results of those studies could not be implemented to improve effective CBR in the real practice. Most previous studies were survey, descriptive, literature review, questionnaires and in-depth interviews as segmental and cross sectional, not comprehensive or holistic study [3, 4, 8, 10, 19-23]. Thus, components of CBR success have challenged.

Meta-analysis and content analysis on CBR researches was done by author and colleagues to identify standard index or effect size or mean correlation among significant independent and dependent variables in CBR phenomena in Thailand. The CBR projects addressed inclusion criteria in which (1) had sufficient statistical matters especially the Pearson product moment correlation or correlation coefficient (r), mean, standard deviation, test, F test and chi-square test for a survey, descriptive or correlation study and an experimental or a quasi-study, (2) had been produced between 1995-2014 and (3) available on public libraries in Thailand and an electronic ThaiLIS database, were purposively collected. The sample was 28 CBR projects consisted of 11 and 17 qualitative and quantitative studies respectively. The main findings showed that, effect size (ES) between significant independent and dependent variables within CBR studies was medium size and varied from 0.21960.2638 ( $\bar{x} / 0.2427, \mathrm{SD}=0.121)$. The main independent variables that reflected characteristics of CBR workers influencing dependent variables or outcomes of CBR included (1) age ( $\mathrm{ES}=0.2196)$, (2) occupation or position $(\mathrm{ES}=0.2317),(3)$ work experience $(\mathrm{ES}=0.2556)$ and $(4)$ education level $(\mathrm{ES}=0.2638)$ of CBR workers [4]

Based on lack of rigorous studies. Additionally, CBR setting and success have been controversial as well as according to recent study of effect size that reflects the strength of the relationship between two variables on a numeric scale. Thus, such four recent independent variables can predict CBR outcome and success. That means it would be great if CBR project were set up with those significant independent variables effecting CBR success as attributive variables or qualifications of CBR workers. The research question is "how will a comprehensive CBR project be conducted based on significant independent variables as qualifications of CBR workers?" Thus, it aims to (1) set up and conduct CBR project in particular voluntary context concerning on significant qualifications of CBR workers including age, education level, occupation or position and work experience of CBR workers as mentioned earlier, (2) conclude and critique phenomena through CBR project as lesson learned.

\section{MATERIALS AND METHODS}

This study is participatory action research (PAR) as Figure 1 adapted from Aimers [24] and consisted of five steps that includes

(1) developing a basis for participation,

(2) data collection and analysis,

(3) planning (master plan of CBR),

(4) action and evaluation and

(5) termination. It aimed to set up and conduct a community based rehabilitation (CBR) in an urban area based on significant variables and particular conditions of previous meta-analysis studies. The particular community and participants in Karkar (assumed name) sub-district, Samut Sakorn Province, Thailand were purposively selected as theoretical criterion sampling with "four-semivoluntary-inclusion" criteria that means trying to find voluntary participants who would be specific inclusion criteria based on previous study reflected significant qualifications of CBR workers including (1) age (more

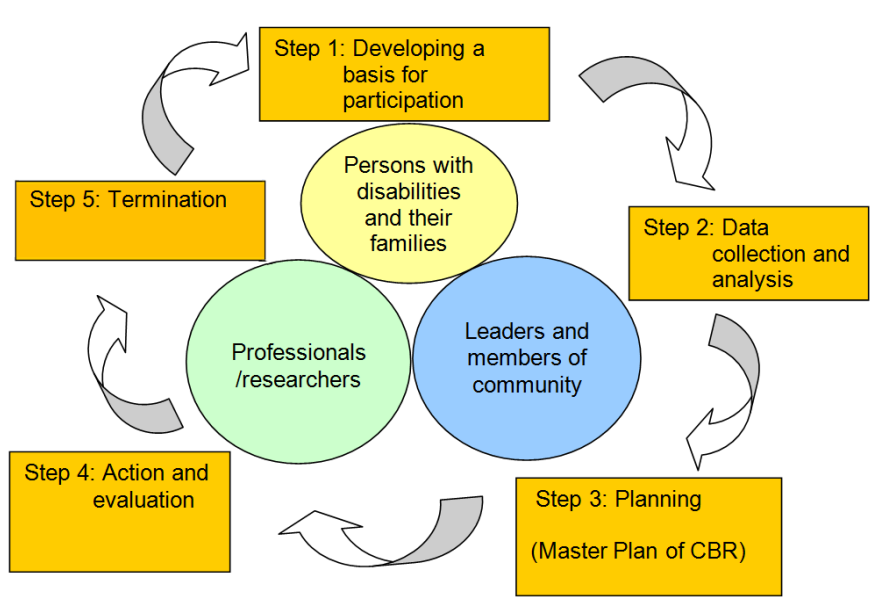

Figure 1: Steps of participatory action research (PAR) on community based rehabilitation (CBR) adapted from Aimers [24]. 


\section{EDORIUM Journals}

Edorium J Disabil Rehabil 2017;3:79-88.

www.edoriumjournals.com/ej/dr

than 23 years), (2) occupation or position (permanent position and salary), (3) work experience (two years or more), (4) education level (secondary school or more) of CBR workers [4].

Data were obtained through various CBR activities including community visits, focus groups, reflective meeting and basic rehabilitation services for PWDs. Verbatim and tape recording of focus groups, participatory observations, field notes and secondary data related were undertaken. Those data were interpreted through such qualitative methods as thematic coding and analytic induction.

\section{RESULTS}

\section{Community context and development of community participation}

Karkar (assumed name), a sub-district has a population of 8642, is located in Mueang District, Samut Sakhon Province, the central part of Thailand. Most of population work in agriculture. According to its metropolitan area being far from Bangkok - the capital city of Thailand around $30 \mathrm{~km}$ away, it has been also partially influenced by industrialization and modern society. The CBR project established four significant independent variables as characteristics of CBR workers with 'semi voluntaryinclusion criteria' as mentioned earlier.

Various approaches were used for community participation and recruitment including formal and informal meeting, personal contact with persons in the community and snow ball techniques through three months of the initial stage. Further inclusion criteria of 'true participant' was frequency of participation that he or she had to voluntarily join CBR activities such as meetings, home visits, coordinating, rehabilitation services for PWDs in community more than 10 of 15 times of such activities through 12 months of CBR conduction.

Finally, the 13 participants/workers were recruited to join the CBR project. Hence, they were selected by 'semi voluntary-inclusion' criteria by purposive and criterion sampling as the sectors and roles for development and implementation of CBR suggested by United Nations Economic and Social Commission for Asia and the Pacific- UNESCAP (1997) and by their own voluntary as well. At the beginning step, the researcher was a leader and then became a facilitator in the middle and final step.

Those 'true participants' were two officials of community health promoting hospital, two officials of the sub-district administrative organization, one official of provincial department, two volunteers in a village, one PWD leader, two care givers of PWDs, one researcher and two research assistants. All participants conducted CBR project through various activities including community visits, focus groups, reflections and basic mobile services for PWDs, etc.
Characteristics and majority of those CBR participants or workers were women $(76.92 \%)$ with a mean age of 45.46 years and range $24-71$ years, obtained bachelor degree (46.45\%), official position (61.54\%), had 3.5 years of experiences in rehabilitation services, social work or related, had positive attitude towards PWDS and services for PWDs. Thus, characteristics of those participants were given in Table 1 and met proposed inclusion criteria.

- Positive lessons learned from this CBR project facilitated by researcher from the initial to termination stage

- Setting up and conducting CBR project in particular voluntary context concerns significant attributive qualifications of CBR workers/ research participants.

This CBR project was set up in Karkar (assumed name) sub-district administrative organization (SAO), Mueang District, Samut Sakhon Province, Thailand. Since community participation is the critical first step of CBR project through participatory action research. CBR participants were recruited based on effect size (ES) between critical independent variables as qualifications of CBR workers and dependent variables as outcome or effectiveness of CBR in CBR phenomena of previous study. In terms of qualifications of CBR workers as independent variables with their effect sizes prioritized including (1) education level ( $\mathrm{ES}=0.2638)$, (2) work experience (ES $=0.2556)$, (3) occupation or position $(\mathrm{ES}=0.2317)$ and (4) age (ES $=0.2196)$ of CBR workers [4] respectively, were inclusion criteria of CBR workers or research participants. Those effect sizes reflected qualifications of CBR workers who graduated in secondary school or more, permanent position and salary, two years or more experience, more than 23-year-old, could predict CBR outcome and success.

However, since participatory action research (PAR) itself, community participation of participants is initiated by their own awareness of research participants, thus CBR workers eventually joined voluntarily as well. Thus, these qualifications were only guidelines rather than rigid inclusion criteria for research participants. Finally, the 13 participants/workers were invited and recruited to join the CBR project as presented.

During the 12 months conducting of CBR, 13 CBR participants provided 15 field visits, depth interviews with over 20 PWDs and their families in the community, two public hearings among 85 participants with PWDs, families, community members, leaders and professionals in local area. There were over 114 PWDs reviewed and registered by CBR participants. The problems and needs of PWDs and their families were prioritized and solved by CBR participants through their own perspectives as following verbal transcriptions.

Participatory action research as mechanism of consciousness raising and transformative learning to enhance quality of life development for PWDs in community. 


\section{EDORIUM Journals}

Edorium J Disabil Rehabil 2017;3:79-88.

www.edoriumjournals.com/ej/dr

Table 1: Characteristic of participants

\begin{tabular}{|c|c|c|c|c|c|}
\hline $\begin{array}{l}\text { Assumed } \\
\text { name }\end{array}$ & Gender & $\begin{array}{c}\text { Age } \\
\text { (years) }\end{array}$ & Education & $\begin{array}{l}\text { Occupation/ } \\
\text { position }\end{array}$ & Work experience \\
\hline Pornpun & Female & 54 & Bachelor & $\begin{array}{l}\text { Director of community health } \\
\text { promoting hospital }\end{array}$ & $\begin{array}{l}\text { - } 30 \text { years as public health nurse } \\
\text { - Five years focused more on PWDs }\end{array}$ \\
\hline Billy & Female & 24 & Bachelor & $\begin{array}{l}\text { Physical therapist of director } \\
\text { community health promoting } \\
\text { hospital }\end{array}$ & $\begin{array}{l}\text { Six years as physical therapist } \\
\text { Five years focused more on PWDs }\end{array}$ \\
\hline Keit & Male & 45 & Bachelor & $\begin{array}{l}\text { Vice-director of sub-district } \\
\text { administrative organization }\end{array}$ & $\begin{array}{l}20 \text { years as local government official } \\
\text { Five years focused on social welfare for } \\
\text { community members }\end{array}$ \\
\hline Somjai & Female & 40 & Bachelor & $\begin{array}{l}\text { Official of sub-district } \\
\text { administrative organization }\end{array}$ & $\begin{array}{l}\text { Eight years as local government official } \\
\text { Three years worked with PWDs in } \\
\text { community }\end{array}$ \\
\hline Suree & Female & 33 & Bachelor & $\begin{array}{l}\text { Official of provincial } \\
\text { department of human security } \\
\text { and social development }\end{array}$ & $\begin{array}{l}\text { Six years as social worker } \\
\text { Two years worked for PWDs in } \\
\text { community }\end{array}$ \\
\hline Wiwa & Female & 71 & Bachelor & $\begin{array}{l}\text { Head of health service } \\
\text { volunteer in village A }\end{array}$ & $\begin{array}{l}15 \text { years as volunteer in community } \\
\text { One year worked for PWDs in } \\
\text { community }\end{array}$ \\
\hline Neung & Female & 46 & $\begin{array}{l}\text { Secondary } \\
\text { School }\end{array}$ & $\begin{array}{l}\text { Head of health service } \\
\text { volunteer in village B }\end{array}$ & $\begin{array}{l}\text { Eight years as volunteer in community } \\
\text { One year worked for PWDs in } \\
\text { community }\end{array}$ \\
\hline Petch & Female & 54 & $\begin{array}{l}\text { Primary } \\
\text { School }\end{array}$ & $\begin{array}{l}\text { Chair of community PWDs } \\
\text { club }\end{array}$ & $\begin{array}{l}\text { Six years as person with physical } \\
\text { disability on wheelchair } \\
\text { Two years of Chair of Community } \\
\text { PWDs Club }\end{array}$ \\
\hline Aun & Female & 50 & $\begin{array}{l}\text { Primary } \\
\text { School }\end{array}$ & $\begin{array}{l}\text { Care giver of PWD and } \\
\text { member community of PWDs } \\
\text { club }\end{array}$ & $\begin{array}{l}\text { Five years as volunteer in community } \\
30 \text { years as PWD care giver (sister of } \\
\text { PWD) } \\
\text { Two years as member of Community } \\
\text { PWDs Club }\end{array}$ \\
\hline Chup & Female & 68 & $\begin{array}{l}\text { Primary } \\
\text { School }\end{array}$ & Care giver of PWD & $\begin{array}{l}20 \text { years as PWD care giver } \\
\text { (grandmother of PWD) }\end{array}$ \\
\hline Vee & Male & 50 & Doctoral & Researcher & $\begin{array}{l}\text { - } 20 \text { years of instructor in rehabilitation } \\
\text { services } \\
\text { - } 15 \text { years of CBR researcher }\end{array}$ \\
\hline Chin & Male & 31 & Master & $\begin{array}{l}\text { Research assistant / Project } \\
\text { coordinator }\end{array}$ & $\begin{array}{l}\text { Three years as coordinator in policy } \\
\text { and community work for PWDs } \\
\text { supported by research fund }\end{array}$ \\
\hline Jarunda & Female & 28 & Master & $\begin{array}{l}\text { Research assistant } \\
\text { /Project coordinator }\end{array}$ & $\begin{array}{l}\text { One years as coordinator in community } \\
\text { work for PWDs supported by research } \\
\text { fund }\end{array}$ \\
\hline
\end{tabular}

Participatory action research is still both philosophy and methodology to help us to know the cycle, nature and dynamic of community participation to help and enhance quality of life of PWDs from a starting point as developing a basis for participation, then data collection and analysis, planning (master plan of CBR), action and evaluation until termination and withdraw of researchers from a community. This CBR cycle reflected not only positive but also negative aspects occurring and how CBR participants coped with this through a holistic cycle of CBR.

As positive things, there were meaningful sharing, learning and supporting among participants and make them empower to step up and overcome challenges they were dealing with. 


\section{EDORIUM Journals}

Edorium J Disabil Rehabil 2017;3:79-88.

Cheausuwantavee $\mathrm{T}$

The one of important steps in the PAR cycle was resource mobilizing and comprehensive planning among stakeholders or participants including data base sharing, pooled resources, budget, alternatives and various services for PWDs.

Billy: "We visited PWDs and their families, but could not visit every PWDs in community. Anyway, we have used two cars of community health promoting hospital and of head of village. Furthermore, a medical doctor from community hospital visited along with us, evaluated and issued medical documents for PWDs as well."

Pornpun: "There is local budget allocated by National Health Security Office. Such budget now is organized by SAO(Sub-district Administrative Organization). Thus, groups of aging or PWDs in community can submit project to SAO for budget allocation."

\section{Exploring and filling the gap with under- standing collaboration}

Additionally, valid data collection and effective information management regarding PWDs in community were also critical issues and seriously discussed among participants through PAR. There have been so far various providers and agencies working and delivering services for PWDs in community including community health promoting hospital, SAO, Provincial Department of Human Security and Social, Center of Special Education, but those agencies have worked separately each other and different data base. As a result, PWDs have gotten services supports ineffectively. These issues were one of agendas critiqued and tried to solved by participants.

Vee: "Only home visit and single data collection might not be helpful, but continuing up-to-date of data, critical analysis and identify their actual problems and needs then support based on those valid problems through cooperation among stakeholders. Some problems could be solved by us, but the rest of problems have to be addressed by other sectors".

Keit: "In case of continuing movement, once related agencies have known these data and to explore more details of all 108 PWDs in community, we will have depth information and what we will go next steps, I believe that."

\section{Physical and medical services as the main issues for quality of life development for PWDs}

Leading participants were a nurse and a physical therapist of community health promoting hospital and community health service volunteers, so the main services focused on health component and physical rehabilitation as medical model that corresponded to need of PWDs in community. So, activities to help PWDs to access wheelchairs were done through participation of participants. After group discussion that all participants discussed in more details and planned to effectively proceed these activities in the next couple of weeks.

Billy: "Based on our home visits, most of PWDs have physical disabilities, lack of any supporting equipment, especially wheelchairs. They want to use wheelchairs, we submitted their request for wheelchairs to provincial hospitals, but it was not successful because wheelchairs were not available."

Vee: "It is not a big deal, Sirindhorn National Medical Rehabilitation Centre, in Nontaburi Province can provide various wheelchairs, but how can we take PWDs to be there for preliminary assessment and bring such wheelchairs back due to long distance and location, we also need particular vehicles to support those PWDs."

Wiwa: "PWDs who want to use wheelchairs in my village are Aun, Kon, Nongluck ... Ummm. Around 4-5 persons."

Pornpun: "My institution (Community Health Promoting Hospital) can provide a van to take 4-5 PWDs there, but the problem is that there is not truck or car to take their wheelchairs back home, we need more vehicles."

Somjai: My Organization (Sub-district Administrative Organization-SAO) has one pick-up truck, I could help in case its necessary to up such wheelchairs."

\section{Employment and income generation of PWDs as the CBR component beyond charity and medical model in commu- nity}

Besides health services, based on data collection and PWDs needs prioritized, job employment and income generation of PWDs are also critical concerns to promote the quality of life for PWDs in this community.

Employment for PWDs is one of CBR matrix that community and participants emphasized to find opportunity for PWDs in community along with business sectors' needs to comply with current laws regarding employment of PWDs in Thailand. Persons with Disabilities Empowerment Act 2007, article 33 states that "For the benefits of the empowerment of persons with disabilities, employers, entrepreneurs and government agency shall employ persons with disabilities to work in the positions suitable for them in proper proportions to the entire number of the employees in their work places. The Minister of Labor shall issue Ministerial Regulations to specify numbers of employees with disabilities that the employers, entrepreneurs and government agencies shall recruit in their work places $[25,26]$. That means such particular laws to promote PWDs to capitalism both market and self-employment without discrimination and provides quota scheme for PWDs by 1.0\% of total employees of public and private organizations. Thus, meeting in community between business employers 


\section{EDORIUM Journals}

Edorium J Disabil Rehabil 2017;3:79-88.

Cheausuwantavee T

and PWDs was held by CBR participants in order to find employment opportunity for PWDs and business/ company sectors as win approach. It did not prove to solve or guarantee employment of PWDs, but it was a starting point and opportunity both PWDs and business sectors in terms of inclusive business. After such meeting and negotiation, those companies reflected some benefits.

Vee: "We have never held meeting among employers, companies, business sectors, persons with disabilities and their families before. So, this is the first time of meeting in our community that will help employers recruit PWDs getting jobs to comply with laws and provide PWDs opportunities for more independent living rather than wait for only small allowance as usual. I now would like to invite companies participating today to reflect what benefits and any suggestion they get and give us respectively."

Bitech: "I today know what are the PWDs needs. Working at home might be alternative options for PWDs that I have never concerned before, I usually focus on working in company only. But so far PWDs could be provided jobs at their homes too. The team with further to explore this alternative possibility for PWDs then."

CS Steel: "I today interviewed three cases of PWDs. They are willing to sell some goods in my company. They also wonder how they can get to my company; no worry about that, I can support them with a car for their transportation free of charge."

Sausage: "I could not recruit any PWDs to get a job, no more time and PWDS in this meeting. Anyhow I today learned more about PWDs and useful information to design what kind of job to suit for them and how to support them at work place."

\section{Sustainability of community based rehabilitation through strategic plan}

Community based rehabilitation (CBR) workers relate to sustainability of CBR services in this community after the researcher terminates the project and withdraws from the community. This project had been conducted through 12 months with 15 various activities such as group discussion, in-depth interview, home visits and services, rehabilitation and referral services, public hearing, etc. through community participation and involvement. By the ways, these activities have been initiative and simultaneous phase to exploreand createpossibility ofCBR set by researcher and some parts of community sectors. For its sustainability over the long run, CBR strategic plan has have existed and integrated into community planning with full participation and continuity. Thus, the CBR four years strategic plan (2016-2019) was written by CBR workers and stakeholders in community based on lessons learned from various activities of research conduction, their sharing and participation. In the preliminary step, the CBR strategic plan had two aims. The first aim was to promote the rights of PWDs to access to crucial basic services including health, education, occupation and social services. Secondly, it aimed to strengthen Subdistrict Administrative Organization (SAO), PWDs group and their networks in community to conduct continuously and systematically CBR services. This strategic plan was made cooperatively and distributed to community leaders and the main local organizations/stakeholders including sub-district administrative organization (SAO), Community Health Promoting Hospital, Provincial Department of Human Security and Social Development, health service volunteer group and community PWDs clubs in community before the end of research project or termination stage.

\section{Negative lessons and challenges learned from CBR phenomena}

Even though there were many positive aspects through the CBR project presented above. there were also challenges and problems or limitations within this CBR conduction that might threaten its sustainability as well.

\section{Uncompleted PAR and CBR cycles}

As per the nature of PAR, development of participation of participants as well as valid needs and problems by their own perspective are important, thus first steps of CBR are:

Step 1 developing a basis for participation and

Step 2 data collection and analysis, required more 6 months with limited time and budget. So, less time was left for step

Step 3 planning (master plan of CBR) as well as step

Step 4 action and evaluation,

Step 5 termination.

Evaluation of CBR outcomes for this project such as using of assistive technologies, services accessibility, independent living and addressing various needs of PWDs in community have not been assessed yet.

\section{Focusing on some parts of elements of health and livelihood component of CBR matrix}

Ideally, CBR matrix consists of five domains including health, education, livelihood, social and empowerment. The health and livelihood domains of this project were emphasized, based on CBR workers and community's expressed interests and need. Home visits, wheelchair referral supports as well as meeting between PWDs and companies for PWDs' employment were conducted. Problems of PWDs in community have been also complicated issues, while this CBR project was lunched as the first time in community with a short period. Basic and updated data regarding PWDs and their needs in community were identified through some community members and participation. Problems of PWDs were 


\section{EDORIUM Journals}

Edorium J Disabil Rehabil 2017;3:79-88.

Cheausuwantavee $\mathrm{T}$

discussed and shared, so many those challenges have been still left and needed to be solved in next steps particularly (1) proper health referral system for PWDs, (2) working and social skills of PWDs in companies and business sectors, (3) valid data of qualified PWDs for employment and (4) lacking of qualified teachers for PWDs in community.

\section{No more sectors of stakeholders in CBR project}

According to global organizations mentioned [27, 28], CBR workers/stakeholders should be seven sectors including (1) PWDs, (2) families of PWDs, (3) community members, (4) governmental organizations as local, regional and national level, (5) nongovernmental organizations as local, regional, national and international level, (6) professionals related such as medical, educational personnel, social works and others, (7) business sectors. For this project, there were only 13 main CBR workers including two officials of community health promoting hospital, two officials sub-district administrative organization, one official of provincial department, two volunteers in village, one leaders of PWDs leader, two care givers of PWDs, one researcher, two research assistants. That means that most of CBR workers were governmental organizations as local medical professionals, local government and research team. There was no business sector and only small group of stakeholders, especially representative of PWDs. It might be risk to strength and continuity of CBR project. Thus, community concern and participation would be further promoted for CBR sustainability.

\section{DISCUSSION}

This study was conducted through participatory action research (PAR) to set up and conduct a community based rehabilitation (CBR) in urban area based on significant variables and particular conditions of previous metaanalysis studies. PAR is still helpful for development of community partnerships, participation and involvement. It increases the cultural competency of rehabilitation services, raising disability awareness and decision making by their own perspective of community participants or CBR workers [29-31].

There were also some positive phenomena helping this CBR project to be run and keep its role. Sharing among CBR workers through PAR helped them understand, have empathy with each other and set up mutual goals with their own perspectives to overcome challenges and address some needs of PWDs in community. Cooperation and networking services were created among these CBR workers as well as capacity building and community resource mobilization were run through $\mathrm{CBR}$ activities. These CBR contributions were also the key components as previous studies [6-8].

It was set up with 13 CBR workers based on their authentic participants, it helps us to understand CBR project as its holistic and dynamic being since initial stagedeveloping a basis for participation to termination stage as a longitudinal study. This study is the same method of some previous studies [7] and differs from majority of other studies that focused on literature review, survey, questionnaire and in-depth interview as a cross-sectional study [5, 6, 8, 10, 19-23].

The important difference from other studies was that it was also set up based on significant variables of previous studies [4]. That study suggested that four independent variables as qualification of CBR workers were also predictable for CBR success and sustainability including education $(E S=0.2914)$, position or socioeconomic status $(\mathrm{ES}=0.2731)$, work experiences $(\mathrm{ES}=0.2365)$, age $(\mathrm{ES}=$ o.2196) that means those who graduated from secondary school or more, had a permanent position and salary, two years or more experiences, more than 20-year-old. There has been no study to set up a project with significant variables from meta-analysis like this study, there were just some content analysis [9]. CBR setting through PAR needed voluntary participation, while no gold standard for optimal participation, conduction, monitoring and tools of CBR. Participation does not occur in a vacuum. It varies depending on context and community culture [31]. Nevertheless, this CBR project might not indicate more control of the four independent variables in a real situation or environment, confounding factors might affect dependent variables, effectiveness or sustainable CBR.

There were some challenges occurring in CBR conduction including uncompleted PAR and CBR cycles, limited focus on only health and livelihood component of CBR matrix, no more sectors of stakeholders in CBR project, lack of proper health referral system for PWDs, lack of working and social skills of PWDs in companies and business sectors, lack of valid data of qualified PWDs for employment and lack of qualified teachers for PWDs in community.

These challenges were similar previous studies. It reflects that these problematic circumstances had been hard to get rid from CBR phenomena through the past two decades both in Thailand and other countries $[7,8,10$, 12-18]. These challenges are not sourced from the CBR workers but from outsiders or stakeholders surrounding them as the big society.

Other limitations of study were limited time and research budget that would be finished one year. So the CBR cycle through PAR was not perfect, uncompleted PAR and CBR cycles. We spent much more time with Step (1) developing a basis for participation, Step (2) data collection and analysis and Step (3) planning (master plan of CBR) before terminate stage and withdrawing from community rather than Step (4) action and evaluation. Since community participation was mainly concerned as 


\section{EDORIUM Journals}

Edorium J Disabil Rehabil 2017;3:79-88.

the key and sustainable component of CBR being. While only 13 main CBR workers involving this project without business sectors and active PWDs in community as CBR concept and practice, thus $\mathrm{CBR}$ matrix services were also limited as general and superficial services as only home visits, general health and occupational guidance, referral and supports for getting wheel chairs. For these limitations, further design to identify and promote key stakeholders as well as follow-up, evaluate and measure CBR output, outcome and its impact would be done while this design is little know and study. Meaningful framework of CBR services and evaluation including ICF concept with deep livelihood, education and cultural component into CBR matrix should be considered. Furthermore, CBR workers training with new paradigm of disability services as social model, rights based and advocacy model are also necessary for effective CBR services [4, 22, 27-29, 31, 32-37].

\section{CONCLUSION}

Community based rehabilitation (CBR) project were purposively and voluntarily set up with four significant independent variables that were characteristics of CBR workers including education, age, occupation, experiences of human services of CBR workers. Those characteristics of CBR workers have proved that they are part of CBR success and sustainability. While there were still some challenges in this CBR phenomena including no more participation of sectors in community especially PWDs themselves, business sector, no comprehensive evaluation of CBR outcomes.

According to research results, the study suggests that

(1) CBR studies through PAR approach in various contexts, significant variables concerned with completed PAR cycle need to be conducted to make various lesson learned, firm conclusions and broad applications,

(2) CBR setting for its continuity and sustainability should consider some variables and factors as follows:

(2.1) in case of limited CBR sectors, the key CBR stakeholders need to come from at least three sectors including

(2.1.1) community leader group,

(2.1.2) PWDs and their care givers

(2.1.3) professionals or CBR facilitators,

(2.2) qualifications of CBR workers/participants as a concerning guideline are

(2.2.1) educational level reflecting knowledge and skills for disability services,

(2.2.2) age reflecting maturity and human relationship skills,

(2.2.3) sufficient socioeconomic status reflecting time devotion and no more benefit and
(2.2.4) attitude and experiences reflecting public and human service mind,

(3) professionals or CBR facilitators should work with community leaders and strengthen PWDs and their care givers. PWDs and their families club/group in community should be promoted,

(4) evaluation and measurement of CBR projects for identifying their quality and quantity as well as effectiveness and efficiency should be done,

(5) after research projects or disability services done by any sectors, document and information should be share each other in community. This approach will help all stakeholders to get to know how community and PWDs are and what they will do next with more cooperative or lesser redundant work.

$* * * * * * * * *$

\section{Acknowledgements}

This article was also part of research titled "The Development of Holistic Community- Based Rehabilitation". Many thanks to all participants, especially ten participants who lived and worked in community for their project participation, movement and data providing and also two coordinators of research project Mr. Chinapong Krisingsom and Ms. Jarunda Junjam for their filed and activity coordination, tape recording and transcription writing. Special thanks Dr. Donald Persons for his support in English editing the manuscript.

\section{Funding}

This research was supported by Mahidol University (Grant 2015).

\section{Author Contribution}

Tavee Cheausuwantavee - Substantial contributions to conception and design, Acquisition of data, Analysis and interpretation of data, Drafting the article, Revising it critically for important intellectual content, Final approval of the version to be published

\section{Guarantor}

The corresponding author is the guarantor of submission.

\section{Conflict of Interest}

Authors declare no conflict of interest.

\section{Copyright}

(C) 2017 Tavee Cheausuwantavee. This article is distributed under the terms of Creative Commons Attribution License which permits unrestricted use, distribution and reproduction in any medium provided the original author(s) and original publisher are properly credited. Please see the copyright policy on the journal website for more information. 


\section{EDORiUM Journals}

Edorium J Disabil Rehabil 2017;3:79-88.

\section{REFRENCES}

1. Thomas M, Thomas JM. A discussion on the relevance of research in the evolution of community based rehabilitation concepts in South Asia. SJDR 1999;5:21-24.

2. Sasad A. Expectation in community based rehabilitation of physically disabled persons: Case study, Bandung District, Udonthani Province [Master's thesis]. Mahidol University, Nakornpathom, Thailand. 1998.

3. Cheausuwantavee T. Community based rehabilitation in Thailand: Current situation and development. Asia Pacific Disability and Rehabilitation Journal. 2005;15:50-66.

4. Cheasuwantavee T, Suwansomrid K, Kraisinfson C. Content and meta-analysis on community based rehabilitation. Mahidol University, Nakornprathom, Thailand. 2015.

5. Sharma U, Ng O. What has worked for bringing out-of-school children with disabilities into regular schools: A literature review. Asia Pacific Disability and Rehabilitation Journal 2014;25:54-75.

6. Mousavi T. The role of community-based rehabilitation in poverty reduction. Asia Pacific Disability and Rehabilitation Journal 2015;26:12539.

7. Sunsern R, Timsuwan B, Lawang L, et al. Integrating community based rehabilitation into overall primary health care: Lessons learned from Thailand. Journal of Nursing and Education 2010;3:99-117.

8. Songyoosook S. The guideline of rehabilitation services for disabled persons by Khemmarat subdistrict administrative organization [Master's thesis]. Khon Kaen University, Khon Kaen, Thailand. 2007.

9. Finkenflügel H, Wolffers I, Huijsman R. The evidence base for community-based rehabilitation: A literature review. Int J Rehabil Res 2005 Sep;28(3):187-201.

10. Piboonwarasak M. Roles of an organization of disabled persons in the disable's capacity building: A case study of association of the disabled persons of Nakornpathom [Master's thesis]. Thammasat University, Bangkok, Thailand. 2003.

11. Cheausuwantavee T. Sexual problems and attitudes toward sexuality of persons with and without disability. Sex Disabil 2002;20:125-34.

12. Tawornkit K. Study of knowledge performance regarding CBR and attitudes toward disabled persons of personnel who worked in public social welfare sector [Master's thesis]. Thammasat University, Bangkok, Thailand. 1995.

13. Devlinger P. Why disabled? The cultural understanding of physical disability in an African Society. In: Ingstad B, Whyte RS, editors. Disability and culture. London: University of California Press; 1995.

14. Nicolaisen I. Person and nonpersons: Disability and personhood among the Punan Bah of Central Borneo. In: Ingstad B, Whyte RS, editors. Disability and Culture. London: University of California Press; 1995.

15. Asch A, Fine M. Women with disabilities: Essays in psychology, culture and politics. Philadelphia: Temple
University Press. 1988.

16. Deshen S, Deshen H. Managing at home: Relationships between blind parents and sighted children. Hum Organ 1989;48:262-7.

17. Sangsorn R. Study of child rehabilitation in community: Case study of the child rehabilitation project in Boauyai district, Nakornratchasrima province [Master's thesis]. Thammasat University, Bangkok, Thailand. 1998.

18. Sentumbwe N. Sighted lovers and blind husbands: Experiences of blind woman in Uganda. In: Ingstad B, Whyte RS, editors. Disability and Culture. London: University of California Press; 1995.

19. Chomnanwaj J. The strategies to develop the role of community based rehabilitation volunteer for disabled people in domestic condition: A study of provincial social development and human security office in central province [Master's thesis]. Thammasat University, Bangkok, Thailand. 2008.

20. Sinsup W. Role of Sub-district administrative for rehabilitation services for persons with disabilities, Kamkeunkeaw community, Ubon Ratchathani Province [Master's thesis]. Khon Kaen University, Khon Kaen, Thailand. 2011.

21. O'Dowd J, MacLachlan M, Khasnabis C, Geiser P. Towards a core set of clinical skills for healthrelated community based rehabilitation in low and middle income countries. Asia Pacific Disability and Rehabilitation Journal 2015;26:5-43.

22. Mijnarends DM, Pham D, Swaans K, Brakel VHW, Wright P. Sustainability criteria for CBR programmes: Two case studies of provincial programmes in Vietnam. Asia Pacific Disability and Rehabilitation Journal 2011;22:3-21.

23. Grandisson M, Hébert M, Thibeault R. A systematic review on how to conduct evaluations in communitybased rehabilitation. Disabil Rehabil 2014;36(4):26575 .

24. Aimers J. Using participatory action research in a local government setting. In: Hughes I, editor. Action Research Electronic Reader. The University of Sydney, 1999. [Available at: http://www.behs.cchs. usyd.edu.au/arow/reader/aimers.htm]

25. Ministry of social development and human security. Persons with disabilities empowerment act. Bangkok, Thailand. 2007. [Available at: http://thailaws.com/ law/t_laws/tlaw0385.pdf]

26. Ministry of Labour. Ministerial regulation on number of persons with disabilities hired and money paid by employer. Bangkok, Thailand. 2011. [Available at: http://thailaws.com/law/t_laws/tlawo385.pdf]

27. Economic and Social Commission for Asia and the Pacific. Understanding community based rehabilitation. United Nation. 1997.

28. ILO, UNESCO, WHO. Community based rehabilitation for and with people with disabilities. Joint position paper. Geneva. 2004.

29. Cheausuwantavee T. Appropriateness and consciousness in community based rehabilitation through participatory action research. Review of Disability Studies 2009;5:53-63. 
30. Gauld S, Smith S, Kendall MB. Using participatory action research in community-based rehabilitation for people with acquired brain injury: From service provision to partnership with Aboriginal communities. Disabil Rehabil 2011;33(19-20):1901-11.

31. Magnusson D, Roe M, Hartman J. Community perspectives: Evaluation of a community-based rehabilitation program in Southern Belize one year post-implementation. Disabil Rehabil 2017 Oct;39(21):2190-7.

32. Cheausuwantavee T. Sexual problems and attitudes toward sexuality of persons with and without disability. The journal of Sexuality and Disability 2002;20:125-34.

33. Thomas M, Thomas MJ. A discussion on some controversies in community-based rehabilitation. Asia Pacific Disability and Rehabilitation Journal 2002;13:1-6.
34. Rule S. Training CBR personnel in South Africa to contribute to the empowerment of persons with disabilities. Disability, CBR and Inclusive Development 2013;24(2):6.

35. Madden RH, Dune T, Lukersmith S, et al. The relevance of the international classification of functioning, disability and health (ICF) in monitoring and evaluating Community-based rehabilitation (CBR). Disabil Rehabil 2014;36(10):826-37.

36. Chung YE, Packer LT. Outcomes and impact of community-based rehabilitation programmes in Chinese communities. Disabil Rehabil 2016;39(8):817-21.

37. Hammel J, Magasi S, Heinemann A, Whiteneck G, Bogner J, Rodriguez E. What does participation mean? An insider perspective from people with disabilities. Disabil Rehabil 2008;30(19):1445-60.
Access full text article on other devices

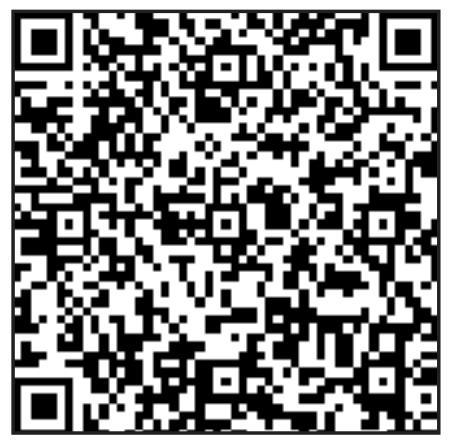

Access PDF of article on other devices

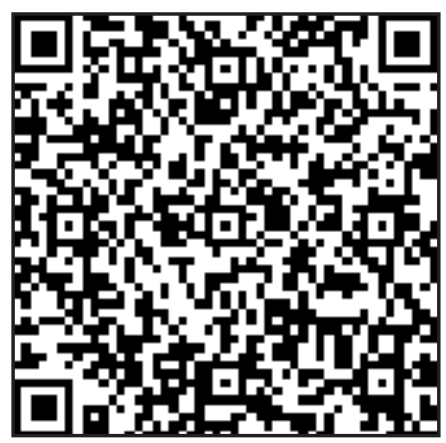

